\title{
Review
}

\section{Rosemary and its protective potencies against COVID-19 and other cytokine storm associated infections: A molecular review}

\author{
Amirabbas Shiravi ${ }^{\mathrm{a}}$, Aliakbar Akbari ${ }^{\mathrm{b}}$, Zahra Mohammadic ${ }^{\mathrm{c}}$, Mohammad-Sadegh Khalilian ${ }^{\mathrm{a}}$, \\ Alireza Zeinalian ${ }^{\mathrm{a}}$ and Mehrdad Zeinalian ${ }^{\mathrm{a}, \mathrm{d}, \mathrm{e}, *}$ \\ ${ }^{a}$ Department of Genetics and Molecular Biology, School of Medicine, Isfahan University of Medical Sciences, \\ Isfahan, Iran \\ ${ }^{\mathrm{b}}$ School of Pharmacy and Pharmaceutical Sciences, Isfahan University of Medical Sciences, Isfahan, Iran \\ ${ }^{\mathrm{c}}$ Department of Biology, Faculty of Sciences, Shahid Bahonar University of Kerman, Kerman, Iran \\ ${ }^{\mathrm{d}}$ Iranians Cancer Control Charity Institute (MACSA), Isfahan, Iran \\ ${ }^{\mathrm{e}}$ Pediatric Inherited Disease Research Center, Research Institute for Primordial Prevention of Non- \\ communicable Disease, Isfahan University of Medical Sciences, Isfahan, Iran
}

Received 17 May 2021

Accepted 11 June 2021

Pre-press 1 September 2021

Published 3 December 2021

\begin{abstract}
.
BACKGROUND: Nowadays, medicinal plants have attracted great interest in treatment of human diseases. Rosemary is a well-known medicinal plant which has been widely used for different therapeutic purposes.

METHODS: This is a narrative review using databases including PubMed, ISI, Scopus, ScienceDirect, Cochrane, and google scholar, the most authoritative articles were searched, screened, and analyzed.

RESULTS: Rosemary is a natural antioxidant which removes reactive oxygen species from tissues and increases expression on Nrf2 gene. Rosemary and its metabolites reduce inflammation by inhibiting production of pro-inflammatory cytokines, decreasing expression of NF- $\kappa \mathrm{B}$, inhibiting infiltration of immune cells to inflamed sites, and affecting gut microbiome. Besides, rosmarinic acid in rosemary extract has positive effects on renin-angiotensin-system. Rosemary affects respiratory system by reducing oxidative stress, inflammation, muscle spasm, and also through anti-fibrotic properties. Carnosic acid is able to penetrate blood-brain-barrier and act against free radicals, ischemia and neurodegeneration in brain. Cardioprotective effects include correcting lipid profile, controlling blood pressure by inhibition of ACE, prevention of atherosclerosis, and reduction of cardiac muscle hypertrophy.

CONCLUSIONS: Accordingly, rosemary supplementation has potential protective effects against COVID-19 and other cytokine storm associated infections, a conclusion that needs more evaluations in the next clinical trials.
\end{abstract}

Keywords: Molecular, protective effects, rosemary, COVID-19, infections

\footnotetext{
${ }^{*}$ Corresponding author: Mehrdad Zeinalian, MD, MPH, PhD, Department of Genetics and Molecular Biology, School of Medicine, Isfahan University of Medical Sciences, Isfahan, Iran. Mobile: +989131098411; Tel./Fax: +9803137929196; E-mail: zeinalianmehrdad@ gmail.com, m.zeinalian@med.mui.ac.ir.
} 


\section{Introduction}

In December 2019, a novel disease with symptoms of pneumonia and acute lung injury and unknown etiology started in Wuhan city of China [1]. This coronavirus disease 2019 (COVID-19), caused by the Severe Acute Respiratory Syndrome Coronavirus-2 (SARS-CoV-2), soon spread all over the world [2,3] and in March 11, 2020, WHO declared it as a pandemic [6]. Coronaviruses (CoVs) are enveloped viruses with single-stranded genome [4] which belong to Orthocoronavirinae subfamily [3]. Although most coronavirus infections are mild, two recent outbreaks of betacoronaviruses, the severe acute respiratory syndrome coronavirus (SARS-CoV) in China, and Middle East respiratory syndrome coronavirus (MERS-CoV) in Saudi Arabia caused severe illnesses with high mortality rates. Comparing to SARS-CoV and MERS-CoV, lower mortality rates but higher transmissibility have been reported for SARS-CoV2 [5].

The novel corona virus is mostly transmitted via respiratory droplets. After arriving to lower respiratory tract, it penetrates to epithelial cells using angiotensin-converting enzyme 2 (ACE2) which acts as a receptor for both SARS-CoV and novel corona virus. After entering respiratory cells, it can activate a strong and uncontrolled immune response and cytokine storm which may finally lead to acute respiratory distress syndrome (ARDS) and multiple organ failure [3]. After 2-14 days of incubation period the symptoms will appear, the most common of which being fever, dry cough, tiredness, headache, shortness of breath or difficulty breathing, and loss of smell and taste [6]. The severity of the disease may vary largely from patient to patient and while some patients are asymptomatic or have mild symptoms, some others may experience severe illness with high mortality [7].

Currently, there is an increasing interest toward medicinal plants for different preventive and therapeutic purposes due to their wide range of health-beneficial properties [8]. Rosemary (Rosmarinus officinalis L. family Lamiaceae) is a medicinal plant originating from the Mediterranean region and now is being cultivated around the world $[9,10]$. This plant has been also widely used for different therapeutic purposes including treatment or prevention of bronchial asthma, headaches, poor circulation, spasmogenic disorders, inflammatory diseases, hepatotoxicity, physical and mental fatigue, heart disease, and cancer [9, 11, 12]. Moreover, rosemary is used as a natural preservative in the food industry, because it can intercept oxidation and microbial contamination [13-16]. Meanwhile, rosemary extracts show several bioactivities such as hepatoprotective, anti-inflammatory, antifungal, anticancer, insecticidal, antioxidant, and antibacterial ones [13, 17-19].

There are several active compounds in rosemary which are responsible for its diverse pharmacological activities. The major compounds present in $r$. officinalis are phenolic compounds, di- and triterpenes and essential oils. The main constituents found in rosemary's essential oil are camphor, 1,8-cineole, $\alpha$-pinene, borneol, $\beta$-pinene, myrcene, and limonene [11, 19-21]; while phenolic compounds mostly consist of rosmarinic acid, chlorogenic acid, and caffeic acid, and rosemary major terpenes are epirosmanol, carnosol, carnosic acid, ursolic acid, and oleanolic acid.

In this review article the potential therapeutic effect of Rosmarinus officinalis $L$. and its active ingredients on COVID-19 and similar infections will be discussed. Figure 1

\section{Method}

The current study is a narrative review in which using some authentic resources including PubMed, ISI, Scopus, ScienceDirect, Cochrane, google scholar, and some preprint databases such as Arxiv, the relevant articles were searched within 2000-2021. Some sensitive keywords were applied to find the most relevant articles, such as, molecular, Rosemary, cytokine storm, inflammation, infection, COVID-19, SARS, and corona virus infection. Finally, the screened full-text articles were evaluated and analyzed using thematic analysis, regarding to the molecular mechanisms of rosemary and its ingredients against COVID-19 and other similar cytokine storm-associated infections. 


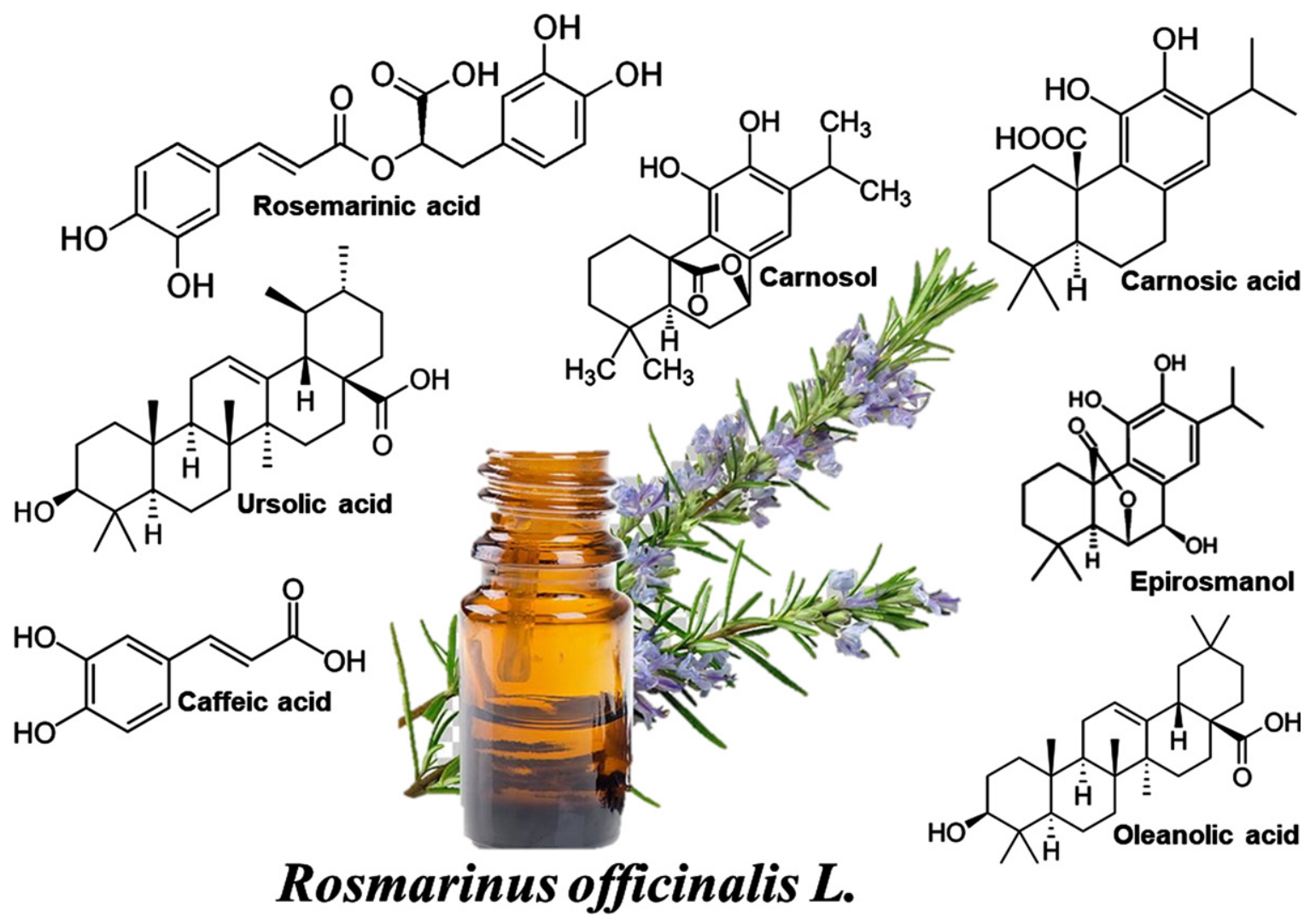

Fig. 1. The chemical structures of the ingredients of Rosemary extract.

\section{Results and discussion}

\subsection{Rosemary and metabolism}

Based on animal studies, rosemary extracts can improve plasma glucose and lipid profiles, and mitigate weight gain [22]. Several studies have declared that rosemary extracts and its well-known components, such as rosmarinic acid, carnosic acid, carnosol, and caffeic acid, may regulate the differentiation of adipocytes and activity of PPAR $\gamma$, and inhibit pancreatic lipase [22-24]. Besides, in vitro researches on HepG2 cells have demonstrated that rosemary extracts favorably regulate lipid and glucose metabolism through activation of multiple pathways, such as activating the AMPK and PPAR signaling pathways, upregulating LDLR, SIRT1, and PGC1 $\alpha$, and downregulating ACC and G6Pase [25]. Upregulation of SIRT1 increases insulin sensitivity, cell glucose consumption, and liver fatty acid oxidation [26, 27]. Likewise, upregulation of LDLR may provide a potential mechanism for the statement that rosemary extracts can lower blood cholesterol level [28]. On the other hand, AMPK activation leads to down-regulate the glycogen synthesis and inducing glycolysis [29]. Moreover, a decreased expression of G6Pase can suppress the gluconeogenesis [30]. Figure 2

\subsection{Rosemary and nutrition}

Rosemary has been used as a culinary spice to improve the flavour of products in a variety of contexts. In the Middle East, it seasons meats and it is used in preparation of tea in Mexico. In India, rosemary leaves flavor 


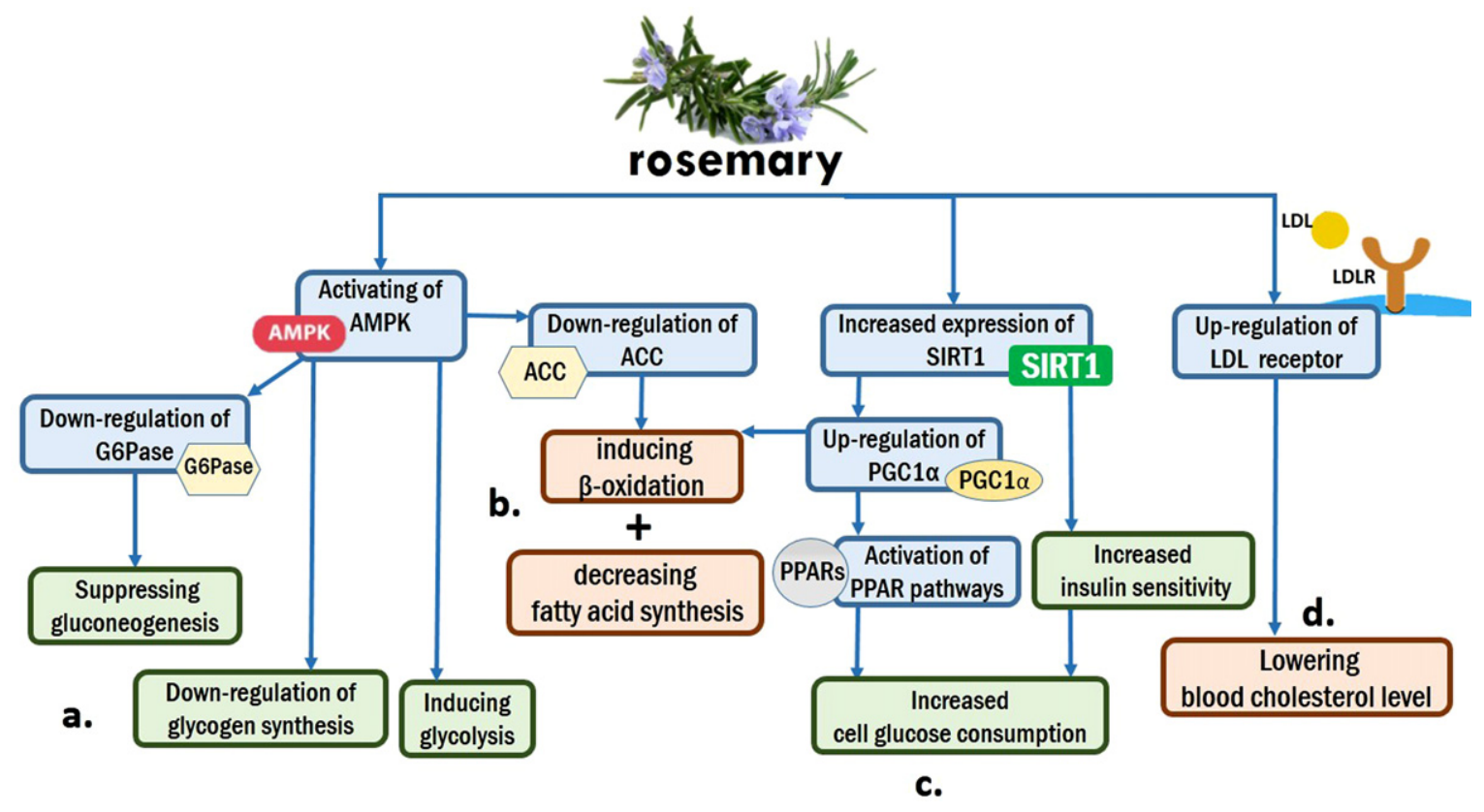

Fig. 2. Rosemary and metabolism: (a). AMPK activation by rosemary regulates blood glucose level by down-regulating glycogen synthesis and inducing glycolysis. Besides, it suppresses gluconeogenesis through down-regulation of G6Pase. (b). Metabolism of lipids is affected by rosemary through inducing $\beta$-oxidation and decreasing fatty acid synthesis. Two mechanisms, down-regulation of ACC by AMPK and up-regulation of PGC1 $\alpha$ by SIRT1, are responsible for these prosesses. (c). Increased expression of SIRT1 by rosemary leads to activation of PPAR pathways and Increasing insulin sensitivity, and finally cause Increased cell glucose consumption. (d). up-regulation of LDL receptor by rosemary can lower blood cholesterol level.

beverages and soups. Besides, it is as part of a marinade for pork, and chicken dishes. [31-34]. Rosemary has a great amount of vitamins and minerals and also a lot of biological activities including antioxidant, antibacterial, and antifungal. Therefore, it is so useful in the industry of food and food packaging [35]. Rosemary extracts can also prevent oxidation and microbial contamination and have been used as food preservatives [36]. Further researches have shown that plant-based dietary supplements containing rosemary, may improve some measures of mood, perceived energy, and have anti-insomnia effect [37, 38]. However, rosemary may reduce non-heme iron absorption as a phenolic-rich antioxidant in foods and so the utilization of dietary iron [39].

\subsection{Rosemary, COVID-19, and renin-angiotensin system}

The renin-angiotensin system (RAS) is classically considered as the modulator of cell proliferation and migration, inflammatory diseases, and the cellular synthesis of several molecules such as cytokines, chemokines, and immunogenic transcription factors [40, 41]. The main enzyme in the RAS is angiotensin-converting enzyme (ACE), a transmembrane zinc metallopeptidase. ACE induces the conversion of angiotensin I (AngI), its most significant substrates, into angiotensin II (AngII) [42, 43]. AngII is an effective agent that induces hypertension and oxidative stress. Moreover, it can increase the reactive oxygen species (ROS) molecules and superoxide levels $[44,45]$.

Rosmarinic acid ( $\alpha$-o-caffeoyl-3,4-dihydroxyphenyl lactic acid, RA), a natural constituent from herbs belonging to the Lamiaceae family, such as rosemary and sage, has significant anti-apoptotic, anti-inflammatory, antioxidant, and ACE inhibitory effects [43, 44]. 
The treatment with RA can decrease ACE expression, and induce ACE2 expression, the homologue of ACE that reduces the ROS effects by generating Ang-[1-9], disrupts the RAS cascade by degrading AngII, and down-regulates angiotensin type 1 receptor (AT1R) [43, 44].

Rather than RAS enzyme, ACE2 is the main receptor for SARS-CoV-2 to entry into human cells [46, 47]. ACE2 overexpression facilitates viral entry and replication in the infected cells. Moreover, it has been demonstrated that the virus down-regulates ACE2 expression and upsets the AngII-Ang 1-7 balance in favor of Ang II, more than the other respiratory infections. It has been shown that the disease severity is correlated with higher amount of AngII levels, so ACE inhibition can improve the disease [48, 49].

RAS blockers are widely used for therapeutic purpose which through an inhibitory effect on AngII formation (ACE inhibitors) or inhibition of AngII type 1 (AT1) receptor (ARBs) can exert their therapeutic effects [49, 50].

According to mechanistic evidence, use of ACEI/ARB for COVID-19 treatment has become controversial. On the one hand, RAS blockades by decreasing Ang II production (ACEIs) or its effects (ARBs), prevent acute lung injury and reduce mortality in COVID-19. On the other hand RAS blockades by increasing ACE2 expression, elevate virulence and infection risk by the virus, however there is no evidence to confirm that ACEIs/ARBs can enhance coronavirus entry by increasing ACE2 expression. As regards, there is need for pharmacoepidemiologic studies to evaluate safety and possible beneficial effect of RAS blockade in COVID-19 [48, 49, 51].

\subsection{The anti-inflammatory effects of rosmarinus officinalis L. in COVID-19}

During the COVID-19 infection, immune system has a vital role in protecting and clearing body from pathogens [52]; but in some patients this immune response becomes un-controlled and happens with high amplitude which results severe and fatal forms of disease. It is shown that during severe forms of COVID-19 infection, patients suffer ARDS, pneumonia and multiple organ failure. Studies suggest that, these organ damages are not simply due to direct effect of virus, but they are because of both replication of virus inside cells and improper function of immune system that invades body organs and mediates tissue damages [53], especially in lungs [54].

Although in a proper immune response we should see activation of $\mathrm{T}$ cells and production of antibodies against that antigen, in impaired immune responses we primarily observe enhanced levels of pro-inflammatory cytokines. This over-production of pro-inflammatory cytokines is known as "cytokine storm" [55]. Different studies have revealed that during COVID-19 infection, this cytokine storm syndrome is associated with high levels of circulating cytokines like: IFN- $\alpha$, IFN- $\gamma$, IL-1 $\beta$, IL-6, IL-12, IL-17, IL-18, IL-33, TNF- $\alpha$, G-CSF, GM-CSF, IP10, C-reactive protein (CRP), MCP1, and MIP1 $\alpha$ [53]. Studies suggest that all COVID-19 patients have increase in IL-6 levels but in more severe cases we see much higher IL-6 levels [56]. This increase in cytokine levels is associated with infiltration and activation of immune cells like monocytes, macrophages, and neutrophils to lungs leading to widespread inflammation of lungs [53, 57] which may finally cause ARDS [52]. Therefore, anti-inflammatory and immunosuppressive therapies have gained great attention especially in severe cases of COVID-19 when immune response is the major problem [54, 55, 58].

Numerous plants have been studied for their anti-inflammatory effects. Rosemary is one of the most important plants studied for this purpose [59]. Guo et al. [60] studied the effect of rosemary extract on MDD on chronic restraint stress (CRS) mice. MDD is associated with increased level of serum inflammatory biomarkers. They found that administration of RE decreased the level of TNF- $\alpha$ and IL-1 $\beta$ in hippocampus, serum and BV-2 microglia cells. The expression of NF- $\kappa \mathrm{B}$ was also reduced in hippocampus and BV-2 microglia cells. They also found that RE can affect gut microbial flora by increasing Lactobacillus and Firmicutes and reducing Bacteroidetes and Proteobacteria [60]. Studies have shown that microbiome and its metabolites have impact on many inflammatory and autoimmune diseases [61] and brain functions [60].

It is shown that carnosic acid in a concentration dependent manner reduces the level of TNFa-mediated cytokines including TNF- $\alpha$, IL-1 $\beta$, IL-6, IL-8, IL-17 and MMP-3 in TNF $\alpha$-induced RA-FLS [62]. Administration of rosemarinic acid have also shown to decrease production of pro-inflammatory cytokines such as TNF- $\alpha$, IL6 , IL-1 $\beta$, TGF- $\beta$, INF- $\beta$, MCP-1, iNOS, IL-10, and NF- $\kappa$ B activation and VEGF in different inflammatory 
problems [63]. Rosemary essential oils have shown to have impact on inflammation by improving TNF- $\alpha$, CRP and MDA levels [64], affecting leucocyte migration and decreasing leucocytes in the inflamed area. Takaki et al. [21] studied anti-inflammatory effect of rosemary essential oils in animal models. Oral administration of REO inhibited inflammation induced by carrageenan in rat's paws and pleural cavity. Similarly Juhás et al. [65] tested REO on carrageenan-induced paw edema and TNBS-induced colitis on ICR mice. REO decreased paw edema and colonic inflammation. Their results showed that REO significantly reduced IL-6 levels and neutrophil infiltration in colon tissue.

\subsection{Antioxidant activity of rosmarinus officinalis L. in COVID-19 patients}

Viral respiratory infections are correlated with oxidative stress which is characterized by increased levels of Reactive Oxygen Spices (ROS). A study conducted by Shao et al. [66] shows that in SARS-CoV-1 infected patients oxidative stress sensitive genes were upregulated [66, 67]. It has also been shown that in COVID-19 patients, amount of neutrophils is increased, and it is well known that neutrophils can enhance ROS levels for using as a defense mechanism [68].

In ARDS patients, particularly in the advanced stages of the disease, severe inflammation and mechanical ventilation with high oxygen concentrations, inevitably elevate oxidant generation both locally and systematically. On the other hand, increased oxidative stress due to release of free radicals and cytokines is the indicator of ARDS $[69,70]$. Therefore, excessive oxidation might be possibly involved in COVID-19. Thus, it is likely that the application of antioxidants would be beneficial in controlling oxidation in coronavirus infected patients. However, further studies are definitely needed to confirm this hypothesis.

Natural antioxidant products, in particular, biologically active compounds found in plants, are getting global popularity because of their efficacy and safety [71]. It is well known that the most pharmacological effects of rosemary are mainly due to high antioxidant activity of its main chemical compounds, which include carnosol, carnosic acid, cyclic diterpene diphenols, ursolic acid, rosmarinic acid, and caffeic acid. The major bioactive constituents with antioxidant capacity are carnosic acid (a phenolic diterpene compound) and carnosol that are implicated in $90 \%$ of the properties [13, 19, 72].

Oxidative stress caused by disruption in antioxidant mechanisms that remove reactive oxygen species (ROS) which contribute to cellular and tissue oxidative stress. Oxidative stress through the oxidization of cellular elements such as membrane lipids, proteins, and DNA causes cellular damage. ROS production can be reduced by antioxidant enzymes including superoxide dismutase, catalase and glutathione peroxidase [73]. There are also dietary supplementation antioxidants like $R$. officinalis $L$. which could act as an antioxidant enzyme and remove superoxide radicals from the tissue $[12,18,19]$. On the other hand, it has been shown that after treatment with $R$. officinalis L., Nrf2 expression is increased. Nuclear factor erythroid 2-related factor 2 (Nrf2), a basic leucine zipper protein, has emerged as a master transcriptional regulator that maintains redox balance by affecting antioxidant genes in response to oxidant stress [74, 75]. The activity of Nrf2 in the elderly is less than others. During oxidative stress situations, Nrf2 becomes released from Keap1, translocates to the nucleus, then binds to the antioxidant response element (RE) in the promoters of various genes, such as antioxidant and detoxifying genes, and elevates their expression. Upregulation of target genes of Nrf2 acts as ROS scavenger and lessen oxidative damage [74, 76]. Studies have shown that carnosic acid is a potent Nrf2 activator [76, 77]. Studies have also revealed that Nrf2 has the ability to prevent viral entry and slow viral replication for a broad range of viruses. PB125 activator of Nrf2 downregulates ACE2 and TMPRSS2, a transmembrane serine protease which plays a critical role in the entrance of SARS-CoV-2 into a human cell. Nrf2 activation also decreases the severity of "cytokine storm" observed in fatal cases of COVID-19 [78].

Studies indicate that both carnosic acid and carnosol have hydroxyl- and peroxyl-radical scavenging properties, and have effective role in inhibition of oxidative hemolysis in blood cells and protecting rat liver microsomal and mitochondrial systems against lipid peroxidation. Other investigations have shown that in oxidative stress circum- 
stances, carnosic acid and carnosol inhibited lipid peroxidation by around $88-100 \%$ and $38-89 \%$, respectively $[13,18,79]$.

Studies based on rosemary structure suggests that the most important elements in rosemary extracts for its antioxidant role are the aromatic ring $(\mathrm{C} 11-\mathrm{C} 12)$ in the catechol group together with the conjugation of the three basic rings. Radical electron caused by oxidation is scavenged by catechol group. During lipid peroxidation inhibition activity of carnosic acid, carnosate radical is formed by hydrogen donation from C-11 position to a lipid radical species, and then radical termination happens by a coupling reaction at the 12- or 14-positions, between carnosate radical and another lipid peroxyl radical, forming epoxides and other intermediary products $[13,18]$.

\subsection{The potential therapeutic effects of rosmarinus officinalis L. for respiratory problems in COVID-19}

Although COVID-19 affects different body organs, respiratory system is the major system affected by the virus. Reproduction of virus inside respiratory cells followed by invasion of the affected lungs by the immune system leads to damage of respiratory tract [80] and causes respiratory symptoms such as shortness of breath, dry cough, fever, decreased blood oxygen level, and acute respiratory distress syndrome (ARDS) [81].

Researches on rosemary suggest that due to properties such as antioxidant [82, 83], reducing muscle spasm of the respiratory tract [84], anti-inflammatory and reducing inflammatory factors in the lungs [85, 86], antimicrobial [87, 88], and anti-fibrotic [89], this plant would be so effective on human respiratory system and its illnesses. Most of the above-mentioned are related to the two main ingredients in rosemary, which include rosmarinic and carnosic acids $[89,90]$.

Properties such as: anti-spasm of the respiratory tract [84], anti-fibrosis and reduction of fibroblast in the lungs [89], increase in prostaglandin (PGE2), decrease in leukotriene (LB4), inhibiting the complement system [82, 90], decrease in histamine and acetylcholine, increase in cellular potassium and decrease in cellular calcium [84], decrease in eosinophil and neutrophils in respiratory system [83, 86], inhibition of enzyme ADA and MPO [91], decrease in interleukins 17-13-6-5-1 and increase in interleukin 10 [88, 91], decrease in NO, TNF- $\alpha$ and cox 2 [88], as well as inhibitory effects on bronchial cell division [92], have led to the use of rosemary to treat respiratory diseases such as bronchitis [82, 90], allergic airway inflammation [93, 94], rhino sinusitis [84, 94], asthma [85, 95], pulmonary fibrosis [89], tuberculosis [88], lung cancer [92], and pneumonia [88, 91]. Various studies have equated the effect of rosemary with the use of corticosteroids and NSAID in the treatment of respiratory diseases $[85,91]$.

\subsection{The cardio-protective effects of rosmarinus officinalis L. in COVID-19}

Serious multiple direct and indirect CVD-attributed cardiac complications may occur in COVID-19 patients, including the acute myocardial injury, myocarditis, arrhythmias, and venous thromboembolism [96, 97].

Based on a recent study, up to $40 \%$ of 138 patients admitted with COVID-19 had pre-existing CVD. Moreover, 7.2\% of the patients had elevated cardiac troponin, suggestive for the virus-induced cardiac injury [98].

Expression of ACE2, possible receptor of SARS-CoV-2, is detected in the heart, providing a link between coronaviruses and the cardiovascular system, and its interaction with the virus may directly cause myocardial inflammation. Besides, the upregulation of 15 pro-inflammatory cytokines could lead to a systemic inflammatory response syndrome that may provide a possible mechanism for multi-organ failure (usually involving the heart) in severe cases. SARS-CoV2 may result in downregulating the myocardial and pulmonary ACE2 pathways [99].

The RAS disturbance and increased AngII lead to an increase in the expression of some molecules like IL1B, IL-6, monocyte chemoattractant protein-1 (MCP-1), and the activation of NOX enzymes. These changes can interfere with NO cycle, having destructive effects on vascular endothelium. Also, AngII can lead to peroxynitrite damage on the vascular endothelial surface by over-expression of Profilin-1 [100]. 
Many of herbal medicines are in the center of the treatment of various disorders such as hyperlipidemia, a major risk factor for atherosclerotic coronary vascular disease [101]. Moreover, Rosmarinus officinalis has been used as a traditional treatment of hypertension and diabetes, which are risk factors for CVD [102, 103]. Rosemary extract decreases the levels of blood glucose and enzyme activities related to cardiac injury and corrects the lipid profile [104].

Today, researchers should screen ACE-inhibitory potencies of plant extracts for new anti-hypertensive agents[105]. Besides, some antihypertensive drugs have been isolated from a number of plant species [106]. For example, water extracts from rosemary LA controls hypertension via inhibition of angiotensin I-converting enzyme (ACE) [107].

Rosemary and its constituents, especially caffeic acid derivatives such as rosmarinic acid, have a therapeutic potential in treatment and prevention of atherosclerosis and ischemic heart disease by Inhibition of lipid peroxidation. Rosemary may also be beneficial in atherosclerosis by increasing production of prostaglandin $\mathrm{E}$ and playing an antioxidant role. Its antioxidant impacts may help minimize consequences of coronary artery disease by reducing the damage resulting from the release of free radicals produced by xanthine oxidase after the reperfusion (reoxygenation) [31].

Half an hour after IV administration, rosemarinic acid (RA) was detected and measured in brain and heart [31]. Based on researches on animal models, RA supplementation in hypertensive rats reduces blood pressure and prevents cardiac injury and hypertrophy. Decrease in endothelin-1 (a vasoconstrictor) level and ACE-I activity, downregulation of the expression of NADPH oxidase p22phox subunit, increase in NO (a vasodilator) levels, and improvement of cardiac anti-oxidant defense were the observed mechanisms for cardio-protective effects of RA [108].

Another animal study has suggested that rosemary significantly decreases NOS activity in heart tissue and subsequently, NO production in the groups treated with rosemary extract compared with the control group [109].

Ursolic acid, a phytonutrient found in some herbs like rosemary, has athero-protective properties by protecting blood monocytes from diabetes-induced dysfunction [110].

Rosmarinus Officinalis L. extracts, such as carnosic acid, play an antioxidant role by inhibition of mRNA expression of the inflammatory genes (IL-6 and MCP-1) and protein levels of multiple agents of mitogen-activated protein kinase (MAPK) signaling pathway (extracellular signal-regulated kinase [ERK] and c-Jun NH2-terminal kinase $[\mathrm{JNK}]$ ), mammalian target of rapamycin (mTOR), and forkhead transcription factor 1(FOXO1 binds to PPAR- $\gamma$ and inhibits its function) [111].

After dietary supplementation with a diet containing Omega-3 plus lecithin, curcumin, and rosemary extracts in a double-blind placebo-controlled trial in CVD patients, a significant decrease was observed in blood pressure, especially the systolic one [112].

Inflammation caused by oxidative stress and cytokines synthesis, such as tumor necrosis factor- $\alpha$ (TNF- $\alpha$ ) and interleukins (IL-1 $\beta$ and IL- 6) may lead to cell death and myocardial infarction. Both reactive oxygen species (ROS) and cytokines may induce the action of metalloproteinases (MMP), which is responsible for causing changes in the function of the heart [113]. R. officinalis L., has been investigated mainly by the presence of bioactive molecules with antioxidant capacities, such as rosmarinic acid, carnosic acid, and carnosol to control the oxidizing agents [114]. Investigations on the effects of rosemary on the heart of infarcted animals has suggested that the supplementation with $R$. officinalis $L$. leaves has reduced muscle hypertrophy and improved diastolic function, verified by increased $\beta$-oxidation of fatty acids and reduced lactate oxidation [115]. Figure 3

\subsection{The neuroprotective effects of rosmarinus officinalis L. in COVID-19}

By presenting of neurologic manifestations such as dizziness, headache, hypogeusia and hyposmia in patients with COVID-19, possible neuroinvasive feature of COVID-19 is in the center of attention [116-118]. Autopsy studies have suggested neuronal necrosis, glial hyperplasia, cerebral edema, neurons' degeneration and detection of SARS genome sequences by RT-PCR, in the brain of COVID-19 patients autopsies [119, 120]. 


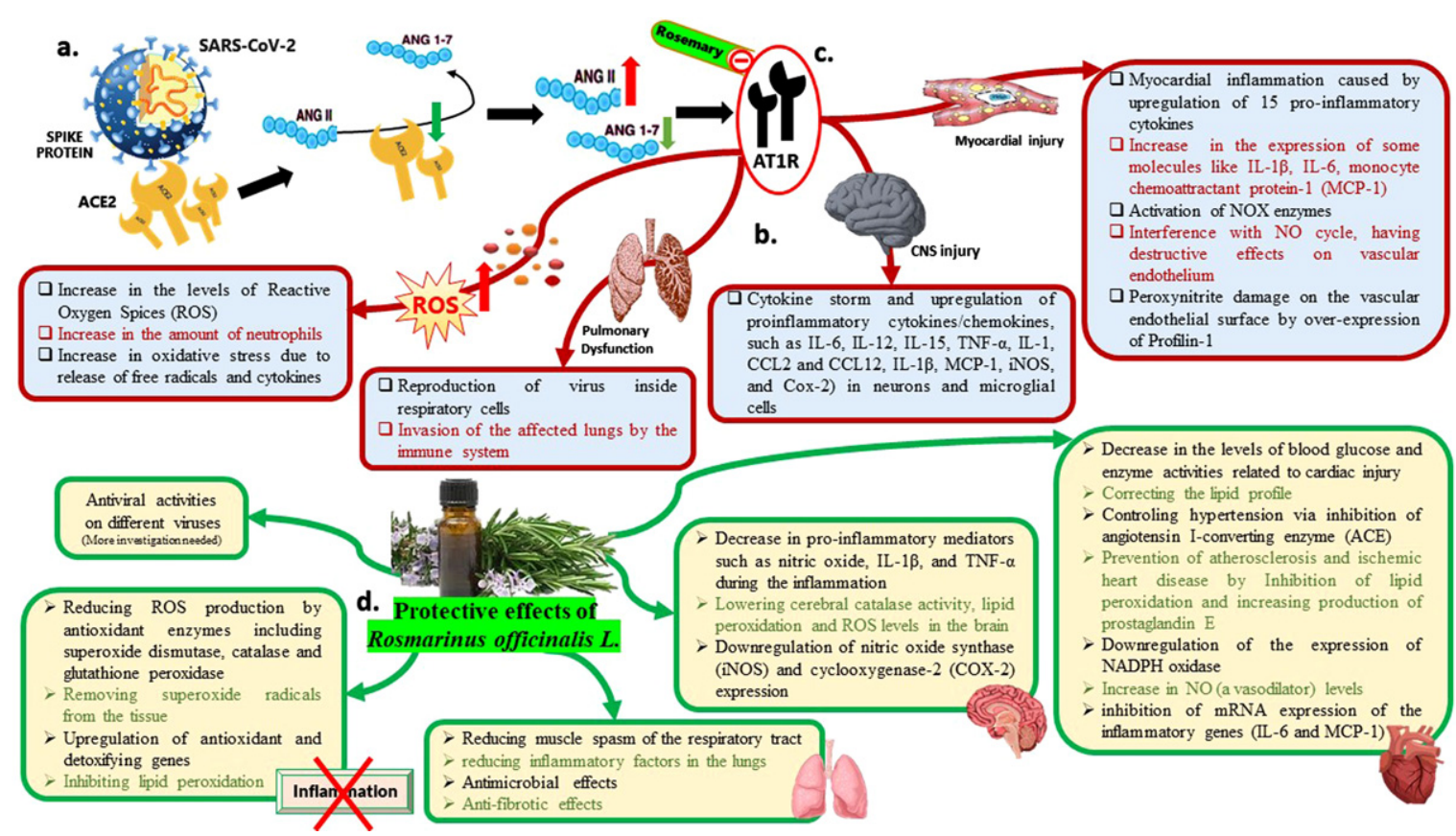

Fig. 3. An infographic picture illustrating the molecular pathway of SARS-CoV-2 pathogenesis and also the molecular pathway of Rosmarinus officinalis L. potencies against COVID-19. (ANG: Angiotensin). (a). ACE2 is the main receptor of SARS-CoV-2 for entering into human cells. It has been demonstrated that the virus down-regulates ACE2 expression and upsets the AngII-Ang 1-7 balance in favor of AngII. (b). Mechanisms of COVID-19 pathogenesis leading to organ damage. (c). Rosemary affects renin-angiotensin system by both ACE suppression and inhibition of AngII binding to its receptor (AT1R: Angiotensin II receptor type 1). (d). The protective effects of Rosmarinus officinalis L. against SARS-CoV-2.

ACE2, possible receptor of SARS-CoV-2, is expressed in neurons and astroglial cells of different parts of CNS $[121,122]$. Intraction of SARS-CoV-2 spike protein and ACE2 can interfere with the balance of the RAS which leads to organ damage by enhancement of Ang II/Ang [1-7] ratio [123].

Researches on animal models have declared that cytokine storm and upregulation of proinflammatory cytokines/chemokines, such as IL-6, IL-12, IL-15, tumor necrosis factor alpha (TNF- $\alpha$ ), IL-1, gamma interferon, CCL2 and CCL12, IL 1 $\beta$, MCP-1, inducible nitric oxide synthase (iNOS), and cyclooxygenase-2 (Cox-2) in SARS-COV infected neurons and microglial cells, can play an immunopathological role in inflamed brains [124-127].

Further studies have suggested that diets rich in phenolic compounds such as rosmarinic acid (RA) may have preventive effects on the development of Alzheimer's disease or dementia (AD) [128].

Based on a research on mice, administration of rosemary oil, by both oral and inhalation route, stimulates the CNS, respiratory and locomotor activity in mice. Besides, alcoholic extracts of $R$. officinalis have antidepressant effect in mice [31]. Rosmarinus officinalis polyphenols produce anti-depressant like effect through monoaminergic and cholinergic functions modulation [129].

Rats, treated with rosemary extracts, showed significantly lower cerebral catalase activity, lipid peroxidation and ROS levels in the brain. Thus, rosemary protects the brain due to its antioxidant role as a free radical scavenger in this organ [109].

Carnosic acid (CA) is able to penetrate the blood-brain barrier. CA protects neurons through its antioxidant activity, both in vitro and in vivo, from glutamate/oxidative stress and cerebral ischemia. It has a neuroprotective 
role by activating the Kelch-like ECH-associated protein 1 (Keap1) / nuclear factor erythroid-2-related factor 2 (Nrf2) pathway [130]. Moreover, antiangiogenic effect of CA can contribute to a neuroprotective effect by prevention of neurodegenerative diseases due to angiogenesis [131].

$R$. officinalis $L$. prevents the mitogen-activated protein kinase (MAPK) phosphorylation, which leads to blockade of nuclear factor Kappa $\mathrm{B}$ (NF-kB) activation. This blocking will downregulate nitric oxide synthase (iNOS) and cyclooxygenase-2 (COX-2) expression. Altogether, pro-inflammatory mediators such as nitric oxide (NO), interleukin 1 beta (IL-1 $\beta$ ), and TNF- $\alpha$, can significantly decrease during the inflammation [115].

Researches on infarcted animals treated with $R$. officinalis $L$. extract have presented that the plant extract contributed to reduction of the neurological deficit and the infarction volume. Also, the edema formation was controlled by protection against rupture of the blood-brain barrier [132].

\subsection{Antiviral effects of rosmarinus officinalis $L$}

Due to limited number of antiviral drugs available in market and increasing number of drug resistant viruses, there is a remarkable interest towards developing effective therapeutic agents against viral pathogens. Recently, there have been many studies done on medicinal herbs, their extracts, and metabolites for their antiviral activities [133, 134].

Among the properties of rosemary, there are antimicrobial properties such as antibacterial, antiviral and antifungal [87]. Nolkemper et al. studied the effect of lamiaceae family aqueous extracts against HSV1 and HSV2. They found that the extracts had inhibitory effects against HSV by interacting with envelope of the virus; thus they are mostly effective on free form of virus. They also found that extracts of Lamiaceae family are effective against acyclovir resistant strain of HSV1 (ACV $\left.{ }^{\text {res }}\right)$ [133].

Carnosol has shown to have an inhibitory effect on HIV [135, 136]; while carnosic acid have shown to be efficient against RNA enveloped respiratory syncytial virus (RSV) by inhibiting viral replication and also inhibiting the initial infection of the virus; however it did not affect influenza A virus replication [135, 137]. It is also shown that rosmarinic acid has antiviral activity against Enterovirus 71 (EV71) by decreasing viral particle production and reducing VP1 protein production [138]. It also had beneficial effects on Japanese encephalitis virus (JEV) infected mice by inhibition of viral replication and also reducing production of pro-inflammatory cytokines [139]. Although rosemary and its metabolites have shown antiviral activities on different viruses, it seems that more detailed studies on the use of this plant to treat viral diseases including SARS-CoV2 are to be done. Figure 3

\section{Conclusion}

Novel corona virus disease which started from Wuhan city, China, soon affected almost all countries around the globe and made the World Health Organization declare it as a global pandemic. Infection by this virus may lead to damages in different body organs by oxidative stress, inflammation and dysregulation of RAS. Rosemarinus officinalis $L$. and its metabolites, especially carrnosic acid and rosemarinic acid, have shown various health benefits in previous studies by inhibiting inflammation and producing pro-inflammatory cytokines, especially IL- 6 and TNF- $\alpha$, and by potent antioxidant activity. Inhibition of ACE by rosemarinic acid is another important action of rosemary. Some remarkable positive actions of rosemary on important body organs are: antiseptic and anti-fibrotic effects on lungs, decreasing blood pressure, inhibiting lipid peroxidation in brain and cardiac tissue, decreasing cardiac injury, preventing neurodegeneration, and suppressing oxidative stress and inflammatory pathways in different organs. Finally, rosemary has shown antiviral effects on some viruses by interacting with virus envelope, inhibiting viral replication and also preventing initial infection of the virus. Based on these data, we suggest that rosemary may be a potential therapeutic option to act against SARS-CoV-2 and reduce its side effects. 


\section{Acknowledgments}

This work was done voluntarily by a research student group.

\section{Conflict of interest}

The authors declare no conflict of interest.

\section{Funding}

None.

\section{References}

[1] Guo W, Li M, Dong Y, Zhou H, Zhang Z, Tian C, et al. Diabetes is a risk factor for the progression and prognosis of COVID-19. Diabetes Metab Res Rev. 2020;n/a(n/a):e3319.

[2] Marhl M, Grubelnik V, Magdič M, Markovič R. Diabetes and metabolic syndrome as risk factors for COVID-19. Diabetes Metab Syndr Clin Res Rev. 2020;14(4):671-7.

[3] Li H, Liu S-M, Yu X-H, Tang S-L, Tang C-K. Coronavirus disease 2019 (COVID-19): current status and future perspectives. Int J Antimicrob Agents. 2020;55(5):105951.

[4] Muniyappa R, Gubbi S. COVID-19 pandemic, coronaviruses, and diabetes mellitus. Am J Physiol-Endocrinol Metab. 2020;318(5):E736-41.

[5] Hussain A, Bhowmik B, do Vale Moreira NC. COVID-19 and diabetes: Knowledge in progress. Diabetes Res Clin Pract. $2020 ; 108142$.

[6] Mohapatra RK, Pintilie L, Kandi V, Sarangi AK, Das D, Sahu R, et al. The recent challenges of highly contagious COVID-19, causing respiratory infections: Symptoms, diagnosis, transmission, possible vaccines, animal models, and immunotherapy. Chem Biol Drug Des.

[7] Singhal T. A review of coronavirus disease-2019 (COVID-19). Indian J Pediatr. 2020;1-6.

[8] Juhás Š, Bukovska A, Čikoš Š, Czikková S, Fabian D, Koppel J. Anti-Inflammatory Effects of Rosmarinus officinalis Essential Oil in Mice. Acta Vet Brno. 2009;78:121-7.

[9] Rašković A, Milanović I, Pavlović N, Ćebović T, Vukmirović S, Mikov M. Antioxidant activity of rosemary (Rosmarinus officinalis L.) essential oil and its hepatoprotective potential. BMC Complement Altern Med. 2014;14(1):225.

[10] Rasoolijazi H, Mehdizadeh M, Soleimani M, Nikbakhte F, Farsani ME, Ababzadeh S. The effect of rosemary extract on spatial memory, learning and antioxidant enzymes activities in the hippocampus of middle-aged rats. 2015;29:11.

[11] Rasha AR, Em A. Modulatory effects of rosemary leaves aqueous extract on doxorubicin-induced histological lesions, apoptosis and oxidative stress in mice. 2010;3(1):22.

[12] de Oliveira JR, Camargo SEA, de Oliveira LD. Rosmarinus officinalis L. (rosemary) as therapeutic and prophylactic agent. J Biomed Sci. 2019;26(1):5.

[13] Nieto G, Ros G, Castillo J. Antioxidant and Antimicrobial Properties of Rosemary (Rosmarinus officinalis, L.): A Review. Medicines. 2018;5(3):98.

[14] Bourhia M, Laasri FE, Aourik H, Boukhris A, Ullah R, Bari A, et al. Antioxidant and Antiproliferative Activities of Bioactive Compounds Contained in Rosmarinus officinalis Used in the Mediterranean Diet. Evid Based Complement Alternat Med. 2019;2019:1-7.

[15] Motlagh MK, Sharafi M, Zhandi M, Mohammadi-Sangcheshmeh A, Shakeri M, Soleimani M, et al. Antioxidant effect of rosemary (Rosmarinus officinalis L.) extract in soybean lecithin-based semen extender following freeze-thawing process of ram sperm. Cryobiology. 2014;69(2):217-22.

[16] Pires MA, Munekata PES, Villanueva NDM, Tonin FG, Baldin JC, Rocha YJP, et al. The Antioxidant Capacity of Rosemary and Green Tea Extracts to Replace the Carcinogenic Antioxidant (BHA) in Chicken Burgers. J Food Qual. 2017;2017:1-6.

[17] Afonso MS, de O Silva AM, Carvalho EB, Rivelli DP, Barros SB, Rogero MM, et al. Phenolic compounds from Rosemary (Rosmarinus officinalis L.) attenuate oxidative stress and reduce blood cholesterol concentrations in diet-induced hypercholesterolemic rats. Nutr Metab. 2013;10(1):19. 
[18] Wijeratne SSK, Cuppett SL. Potential of Rosemary (Rosemarinus officinalis L.) Diterpenes in Preventing Lipid HydroperoxideMediated Oxidative Stress in Caco-2 Cells. J Agric Food Chem. 2007;55(4):1193-9.

[19] Posadas SJ, Caz V, Largo C, De la Gándara B, Matallanas B, Reglero G, et al. Protective effect of supercritical fluid rosemary extract, Rosmarinus officinalis, on antioxidants of major organs of aged rats. Exp Gerontol. 2009;44(6-7):383-9.

[20] Andrade JM, Faustino C, Garcia C, Ladeiras D, Reis CP, Rijo P. Rosmarinus officinalis L.: an update review of its phytochemistry and biological activity. Future Sci OA. 2018;4(4):FSO283.

[21] Takaki I, Bersani-Amado L, Vendruscolo A, Sartoretto S, Diniz S, Bersani-Amado C, et al. Anti-inflammatory and antinociceptive effects of Rosmarinus officinalis L. essential oil in experimental animal models. J Med Food. 2008;11(4):741-6.

[22] Ibarra A, Cases J, Roller M, Chiralt-Boix A, Coussaert A, Ripoll C. Carnosic acid-rich rosemary (Rosmarinus officinalis L.) leaf extract limits weight gain and improves cholesterol levels and glycaemia in mice on a high-fat diet. Br J Nutr. 2011;106(8):1182-9.

[23] Rau O, Wurglics M, Paulke A, Zitzkowski J, Meindl N, Bock A, et al. Carnosic acid and carnosol, phenolic diterpene compounds of the labiate herbs rosemary and sage, are activators of the human peroxisome proliferator-activated receptor gamma. Planta Med. 2006;72(10):881-7.

[24] Takahashi T, Tabuchi T, Tamaki Y, Kosaka K, Takikawa Y, Satoh T. Carnosic acid and carnosol inhibit adipocyte differentiation in mouse 3T3-L1 cells through induction of phase 2 enzymes and activation of glutathione metabolism. Biochem Biophys Res Commun. 2009;382(3):549-54.

[25] Tu Z, Moss-Pierce T, Ford P, Jiang TA. Rosemary (Rosmarinus officinalis L.) extract regulates glucose and lipid metabolism by activating AMPK and PPAR pathways in HepG2 cells. J Agric Food Chem. 2013;61(11):2803-10.

[26] Sun C, Zhang F, Ge X, Yan T, Chen X, Shi X, et al. SIRT1 improves insulin sensitivity under insulin-resistant conditions by repressing PTP1B. Cell Metab. 2007;6(4):307-19.

[27] Purushotham A, Schug TT, Xu Q, Surapureddi S, Guo X, Li X. Hepatocyte-specific deletion of SIRT1 alters fatty acid metabolism and results in hepatic steatosis and inflammation. Cell Metab. 2009;9(4):327-38.

[28] Labban L, Mustafa UE-S, Ibrahim YM. The Effects of Rosemary (Rosmarinus officinalis) Leaves Powder on Glucose Level, Lipid Profile and Lipid Perodoxation. Int J Clin Med. 2014;05(06):297-304.

[29] Peeters A, Fraisl P, van den Berg S, van Themaat EVL, Van Kampen A, Rider MH, et al. Carbohydrate metabolism is perturbed in peroxisome-deficient hepatocytes due to mitochondrial dysfunction, AMP-activated protein kinase (AMPK) activation, and peroxisome proliferator-activated receptor $\gamma$ coactivator $1 \alpha$ (PGC-1 $\alpha$ ) suppression. J Biol Chem. 2011;286(49):42162-79.

[30] Kim YD, Park K-G, Lee Y-S, Park Y-Y, Kim D-K, Nedumaran B, et al. Metformin inhibits hepatic gluconeogenesis through AMP-activated protein kinase-dependent regulation of the orphan nuclear receptor SHP. Diabetes. 2008;57(2):306-14.

[31] Al-Sereiti MR, Abu-Amer KM, Sena P. Pharmacology of rosemary (Rosmarinus officinalis Linn.) and its therapeutic potentials. 1999

[32] Mulinacci N, Innocenti M, Bellumori M, Giaccherini C, Martini V, Michelozzi M. Storage method, drying processes and extraction procedures strongly affect the phenolic fraction of rosemary leaves: an HPLC/DAD/MS study. Talanta. 2011;85(1):167-76.

[33] Ulbricht C, Abrams TR, Brigham A, Ceurvels J, Clubb J, Curtiss W, et al. An evidence-based systematic review of rosemary (Rosmarinus officinalis) by the Natural Standard Research Collaboration. J Diet Suppl. 2010;7(4):351-413.

[34] de Raadt P, Wirtz S, Vos E, Verhagen H. Short review of extracts of rosemary as a food additive. Eur J Nutr Food Saf. 2015;126-37.

[35] Ribeiro-Santos R, Carvalho-Costa D, Cavaleiro C, Costa HS, Albuquerque TG, Castilho MC, et al. A novel insight on an ancient aromatic plant: The rosemary (Rosmarinus officinalis L.). Trends Food Sci Technol. 2015;45(2):355-68.

[36] Nieto G, Ros G, Castillo J. Antioxidant and Antimicrobial Properties of Rosemary (Rosmarinus officinalis, L.): A Review. Medicines. 2018;5(3):98.

[37] Bloomer RJ, MacDonnchadh JJ, Moran RG, Timmcke JQ, Qin B. Impact of a Dietary Supplement Containing Rosemary and Daylily on Biochemical Markers of Cognitive Health, Sleep Quality and Related Variables in Men and Women. Health (N Y). 2016;8(13):1307-22.

[38] Solhi H, Salehi B, Alimoradian A, Pazouki S, Taghizadeh M, Saleh AM, et al. Beneficial effects of Rosmarinus officinalis for treatment of opium withdrawal syndrome during addiction treatment programs: a clinical trial. Addict Health. 2013;5(3-4):90.

[39] Samman S, Sandström B, Toft MB, Bukhave K, Jensen M, Sørensen SS, et al. Green tea or rosemary extract added to foods reduces nonheme-iron absorption. Am J Clin Nutr. 2001;73(3):607-12.

[40] Satou R, Penrose H, Navar LG. Inflammation as a Regulator of the Renin-Angiotensin System and Blood Pressure. Curr Hypertens Rep. 2018;20(12):100.

[41] S.A. Capettini L, Montecucco F, Mach F, Stergiopulos N, A.S. Santos R, F. da Silva R. Role of Renin-Angiotensin System in Inflammation, Immunity and Aging. Curr Pharm Des. 2012;18(7):963-70.

[42] Agić D, Abramić M, Rastija V, Vuković R. Polyphenolic Flavonoids and Metalloprotease Inhibition: Applications to Health and Disease. In: Polyphenols: Mechanisms of Action in Human Health and Disease [Internet]. Elsevier; 2018 [cited 2020 Jun 1]. pp. 33-40. Available from: https://linkinghub.elsevier.com/retrieve/pii/B9780128130063000040 
[43] Liu Q, Tian J, Xu Y, Li C, Meng X, Fu F. Protective Effect of RA on Myocardial Infarction-Induced Cardiac Fibrosis via AT1R/p38 MAPK Pathway Signaling and Modulation of the ACE2/ACE Ratio. J Agric Food Chem. 2016;64(35):6716-22.

[44] Prasannarong M, Saengsirisuwan V, Surapongchai J, Buniam J, Chukijrungroat N, Rattanavichit Y. Rosmarinic acid improves hypertension and skeletal muscle glucose transport in angiotensin II-treated rats. BMC Complement Altern Med. 2019;19(1):165.

[45] Silva RAP, Chu Y, Miller JD, Mitchell IJ, Penninger JM, Faraci FM, et al. Impact of ACE2 Deficiency and Oxidative Stress on Cerebrovascular Function With Aging. Stroke. 2012;43(12):3358-63.

[46] Samavati L, Uhal BD. ACE2, Much More Than Just a Receptor for SARS-COV-2. Front Cell Infect Microbiol. 2020;10:317.

[47] Meng J, Xiao G, Zhang J, He X, Ou M, Bi J, et al. Renin-angiotensin system inhibitors improve the clinical outcomes of COVID-19 patients with hypertension. Emerg Microbes Infect. 2020;9(1):757-60.

[48] Hanff TC, Harhay MO, Brown TS, Cohen JB, Mohareb AM. Is There an Association Between COVID-19 Mortality and the Renin-Angiotensin System? A Call for Epidemiologic Investigations. Clin Infect Dis. 2020;ciaa329.

[49] Bahat G. COVID-19 and the Renin Angiotensin System: Implications for the Older Adults. J Nutr Health Aging [Internet]. 2020 Jun 4 [cited 2020 Jun 24]; Available from: http://link.springer.com/10.1007/s12603-020-1403-7

[50] Marquez A, Wysocki J, Pandit J, Batlle D. An update on ACE2 amplification and its therapeutic potential. Acta Physiol [Internet]. 2020 Jun 17 [cited 2020 Jun 24]; Available from: https://onlinelibrary.wiley.com/doi/abs/10.1111/apha.13513

[51] Danser AHJ, Epstein M, Batlle D. Renin-Angiotensin System Blockers and the COVID-19 Pandemic: At Present There Is No Evidence to Abandon Renin-Angiotensin System Blockers. Hypertension. 2020;75(6):1382-5.

[52] Tufan A, GÜLER AA, Matucci-Cerinic M. COVID-19, immune system response, hyperinflammation and repurposing antirheumatic drugs. Turk J Med Sci. 2020;50(SI-1):620-32.

[53] Meftahi GH, Jangravi Z, Sahraei H, Bahari Z. The possible pathophysiology mechanism of cytokine storm in elderly adults with COVID-19 infection: the contribution of "inflame-aging." Inflamm Res. 2020;1-15.

[54] Tay MZ, Poh CM, Rénia L, MacAry PA, Ng LF. The trinity of COVID-19: immunity, inflammation and intervention. Nat Rev Immunol. 2020;1-12.

[55] Theoharides T, Conti P. Dexamethasone for COVID-19? Not so fast. J Biol Regul Homeost Agents. 2020;34(3):10-23812.

[56] García LF. Immune response, inflammation, and the clinical spectrum of COVID-19. Front Immunol. 2020;11:1441.

[57] Solun B, Shoenfeld Y. Inhibition of metalloproteinases in therapy for severe lung injury due to COVID-19. Med Drug Discov. 2020;100052.

[58] Stebbing J, Phelan A, Griffin I, Tucker C, Oechsle O, Smith D, et al. COVID-19: combining antiviral and anti-inflammatory treatments. Lancet Infect Dis. 2020;20(4):400-2.

[59] Justo OR, Simioni PU, Gabriel DL, Tamashiro WM da SC, Rosa P de TV, Moraes ÂM. Evaluation of in vitro anti-inflammatory effects of crude ginger and rosemary extracts obtained through supercritical CO 2 extraction on macrophage and tumor cell line: the influence of vehicle type. BMC Complement Altern Med. 2015;15(1):1-15.

[60] Guo Y, Xie J, Li X, Yuan Y, Zhang L, Hu W, et al. Antidepressant effects of rosemary extracts associate with anti-inflammatory effect and rebalance of gut microbiota. Front Pharmacol. 2018;9:1126.

[61] Clemente JC, Manasson J, Scher JU. The role of the gut microbiome in systemic inflammatory disease. Bmj. $2018 ; 360$.

[62] Liu M, Zhou X, Zhou L, Liu Z, Yuan J, Cheng J, et al. Carnosic acid inhibits inflammation response and joint destruction on osteoclasts, fibroblast-like synoviocytes, and collagen-induced arthritis rats. J Cell Physiol. 2018;233(8):6291-303.

[63] Nadeem M, Imran M, Aslam Gondal T, Imran A, Shahbaz M, Muhammad Amir R, et al. Therapeutic potential of rosmarinic acid: A comprehensive review. Appl Sci. 2019;9(15):3139.

[64] Elbahnasawy AS, Valeeva E, El-Sayed EM, Rakhimov I. The impact of thyme and rosemary on prevention of osteoporosis in rats. J Nutr Metab. 2019;2019.

[65] Juhás Š, Bukovská A, Čikoš Š, Czikková S, Fabian D, Koppel J. Anti-inflammatory effects of Rosmarinus officinalis essential oil in mice. Acta Vet Brno. 2009;78(1):121-7.

[66] Shao H, Lan D, Duan Z, Liu Z, Min J, Zhang L, et al. Upregulation of Mitochondrial Gene Expression in PBMC from Convalescent SARS Patients. J Clin Immunol. 2006;26(6):546-54.

[67] Shneider A, Kudriavtsev A, Vakhrusheva A. Can melatonin reduce the severity of COVID-19 pandemic? Int Rev Immunol. 2020;1-10.

[68] Baqi HR, M. Farag HA, El Bilbeisi AHH, Askandar RH, El Afifi AM. Oxidative Stress and Its Association with COVID-19: A Narrative Review. Kurd J Appl Res. 2020;97-105.

[69] Zhang R, Wang X, Ni L, Di X, Ma B, Niu S, et al. COVID-19: Melatonin as a potential adjuvant treatment. Life Sci. 2020;250:117583.

[70] Cheng RZ. Can early and high intravenous dose of vitamin C prevent and treat coronavirus disease 2019 (COVID-19)? Med Drug Discov. 2020;5:100028.

[71] Lourenço SC, Moldão-Martins M, Alves VD. Antioxidants of natural plant origins: From sources to food industry applications. Molecules. 2019;24(22):4132. 
[72] Frankel EN, Huang S-W, Aeschbach R, Prior E. Antioxidant Activity of a Rosemary Extract and Its Constituents, Carnosic Acid, Carnosol, and Rosmarinic Acid, in Bulk Oil and Oil-in-Water Emulsion. J Agric Food Chem. 1996;44(1):131-5.

[73] Pizzino G, Irrera N, Cucinotta M, Pallio G, Mannino F, Arcoraci V, et al. Oxidative stress: harms and benefits for human health. Oxid Med Cell Longev. 2017;2017.

[74] Zhao S, Ghosh A, Lo C-S, Chenier I, Scholey JW, Filep JG, et al. Nrf2 Deficiency Upregulates Intrarenal Angiotensin-Converting Enzyme-2 and Angiotensin 1-7 Receptor Expression and Attenuates Hypertension and Nephropathy in Diabetic Mice. Endocrinology. 2018;159(2):836-52.

[75] Ma A. The Role of Central ACE2 and Nrf2 in Sympatho-Excitation: Responses to Central Angiotensin II. :146.

[76] Xie Z, Zhong L, Wu Y, Wan X, Yang H, Xu X, et al. Carnosic acid improves diabetic nephropathy by activating Nrf2/ARE and inhibition of NF- $\kappa$ B pathway. Phytomedicine. 2018;47:161-73.

[77] de Oliveira MR, Ferreira GC, Schuck PF. Protective effect of carnosic acid against paraquat-induced redox impairment and mitochondrial dysfunction in SH-SY5Y cells: Role for PI3K/Akt/Nrf2 pathway. Toxicol In Vitro. 2016;32:41-54.

[78] McCord JM, Hybertson BM, Cota-Gomez A, Gao B. Nrf2 Activator PB125 ${ }^{\circledR}$ as a Potential Therapeutic Agent Against COVID-19 [Internet]. Cell Biology; 2020 May [cited 2020 Jun 24]. Available from: http://biorxiv.org/lookup/doi/10.1101/2020.05.16.099788

[79] Yang Y, Song X, Sui X, Qi B, Wang Z, Li Y, et al. Rosemary extract can be used as a synthetic antioxidant to improve vegetable oil oxidative stability. Ind Crops Prod. 2016;80:141-7.

[80] Yuki K, Fujiogi M, Koutsogiannaki S. COVID-19 pathophysiology: A review. Clin Immunol. 2020;108427.

[81] Clinical features of patients infected with 2019 novel coronavirus in Wuhan, China - ScienceDirect [Internet]. [cited 2020 Jun 15]. Available from: https://www.sciencedirect.com/science/article/pii/S0140673620301835

[82] al-Sereiti MR, Abu-Amer KM, Sen P. Pharmacology of rosemary (Rosmarinus officinalis Linn.) and its therapeutic potentials. Indian J Exp Biol. 1999;37(2):124-30.

[83] Inoue K-I, Takano H, Shiga A, Fujita Y, Makino H, Yanagisawa R, et al. Effects of volatile constituents of a rosemary extract on allergic airway inflammation related to house dust mite allergen in mice. Int J Mol Med. 2005;16(2):315-9.

[84] Aqel MB. Relaxant effect of the volatile oil of Romarinus officinalis on tracheal smooth muscle. J Ethnopharmacol. 1991;33(1):57-62.

[85] Eftekhar N, Moghimi A, Boskabady MH. Prophylactic effect of rosmarinic acid on tracheal responsiveness, white blood cell count and oxidative stress markers in lung lavage of sensitized rats. Pharmacol Rep. 2018;70(1):119-25.

[86] Sanbongi C, Takano H, Osakabe N, Sasa N, Natsume M, Yanagisawa R, et al. Rosmarinic acid in perilla extract inhibits allergic inflammation induced by mite allergen, in a mouse model. Clin Htmlent Glyphamp Asciiamp Exp Allergy. 2004;34(6):971-7.

[87] Aslani A, Zolfaghari B, Fereidani Y. Design, formulation, and evaluation of a herbal gel contains melissa, sumac, licorice, rosemary, and geranium for treatment of recurrent labial herpes infections. Dent Res J. 2018;15(3):191-200.

[88] Zerin T, Lee M, Jang WS, Nam K-W, Song H-Y. Anti-inflammatory potential of ursolic acid in Mycobacterium tuberculosis-sensitized and Concanavalin A-stimulated cells. Mol Med Rep. 2016;13(3):2736-44.

[89] Bahri S, Mies F, Ben Ali R, Mlika M, Jameleddine S, Mc Entee K, et al. Rosmarinic acid potentiates carnosic acid induced apoptosis in lung fibroblasts. PLoS ONE [Internet]. 2017 Sep 6 [cited 2020 May 31];12(9). Available from: https://www.ncbi.nlm.nih.gov/pmc/articles/PMC5587316/

[90] Begum A, Sandhya S, Ali SS, Vinod KR, Reddy S, Banji D. An in-depth review on the medicinal flora rosmarinus officinalis (lamiaceae). : 13 .

[91] da Rosa J, Facchin B, Bastos J, Siqueira M, Micke G, Dalmarco E, et al. Systemic Administration of Rosmarinus officinalis Attenuates the Inflammatory Response Induced by Carrageenan in the Mouse Model of Pleurisy. Planta Med. 2013;79(17):1605-14.

[92] Offord EA, Macé K, Avanti O, Pfeifer AMA. Mechanisms involved in the chemoprotective effects of rosemary extract studied in human liver and bronchial cells. Cancer Lett. 1997;114(1-2):275-81.

[93] Ben-Arye E, Dudai N, Eini A, Torem M, Schiff E, Rakover Y. Treatment of Upper Respiratory Tract Infections in Primary Care: A Randomized Study Using Aromatic Herbs. Evid-Based Complement Altern Med ECAM [Internet]. 2011 [cited 2020 May 31 ];2011. Available from: https://www.ncbi.nlm.nih.gov/pmc/articles/PMC2967840/

[94] Kehrl W, Sonnemann U, Dethlefsen U. Therapy for acute nonpurulent rhinosinusitis with cineole: results of a double-blind, randomized, placebo-controlled trial. The Laryngoscope. 2004;114(4):738-42.

[95] de Albuquerque UP, de Medeiros PM, de Almeida ALS, Monteiro JM, de Freitas Lins Neto EM, de Melo JG, et al. Medicinal plants of the caatinga (semi-arid) vegetation of NE Brazil: A quantitative approach. J Ethnopharmacol. 2007;114(3):325-54.

[96] Clinical aspects and outcomes of 70 patients with Middle East respiratory syndrome coronavirus infection: a singlecenter experience in Saudi Arabia | Elsevier Enhanced Reader [Internet]. [cited 2020 Mar 25]. Available from: https://reader.elsevier.com/reader/sd/pii/S1201971214016221?token=47ACD734E193302ACCB9F53CA0EF7561D468D95B452 0A21BD7FC4A4B4C0C0E10FED8B1AEC6F9FB94DE7A16F52339804B 
[97] Driggin E, Madhavan MV, Bikdeli B, Chuich T, Laracy J, Bondi-Zoccai G, et al. Cardiovascular Considerations for Patients, Health Care Workers, and Health Systems During the Coronavirus Disease 2019 (COVID-19) Pandemic. J Am Coll Cardiol [Internet]. 2020 Mar 19 [cited 2020 Mar 25]; Available from: http://www.sciencedirect.com/science/article/pii/S0735109720346374

[98] Wang D, Hu B, Hu C, Zhu F, Liu X, Zhang J, et al. Clinical Characteristics of 138 Hospitalized Patients With 2019 Novel Coronavirus-Infected Pneumonia in Wuhan, China. JAMA. 2020;323(11):1061-9.

[99] Xiong T-Y, Redwood S, Prendergast B, Chen M. Coronaviruses and the cardiovascular system: acute and long-term implications. Eur Heart J. 2020; ehaa231.

[100] Shiravi AA, Saadat M, Abdollahi Z, Miar P, Khanahmad H, Zeinalian M. Vitamin D can be effective against COVID19 and other similar viral infections: A review on molecular aspects [Internet]. Zenodo; 2020 Apr [cited 2020 Jun 18]. Available from: https://zenodo.org/record/3779934\#.XuuSh2gzZPY

[101] Huang TH-W, Kota BP, Razmovski V, Roufogalis BD. Herbal or Natural Medicines as Modulators of Peroxisome ProliferatorActivated Receptors and Related Nuclear Receptors for Therapy of Metabolic Syndrome. Basic Clin Pharmacol Toxicol. 2005;96(1):3-14.

[102] Amel B. Traditional treatment of high blood pressure and diabetes in Souk Ahras District. J Pharmacogn Phytother. 2013;5(1):12-20.

[103] Ramadan KS, Khalil OA, Danial EN, Alnahdi HS, Ayaz NO. Hypoglycemic and hepatoprotective activity of Rosmarinus officinalis extract in diabetic rats. J Physiol Biochem. 2013;69(4):779-83.

[104] Alnahdi HS. Effect of Rosmarinus officinalis extract on some cardiac enzymes of streptozotocin-induced diabetic rats. J Health Sci. 2012;2(4):33-7.

[105] Wagner H, Elbl G, Lotter H, Guinea M. Evaluation of natural products as inhibitors of angiotensin I-converting enzyme (ACE). Pharm Pharmacol Lett. 1991;1:15-8.

[106] Actis-Goretta L, Ottaviani JI, Keen CL, Fraga CG. Inhibition of angiotensin converting enzyme (ACE) activity by flavan-3-ols and procyanidins. FEBS Lett. 2003;555(3):597-600.

[107] Kwon Y-II, Vattem DA, Shetty K. Evaluation of clonal herbs of Lamiaceae species for management of diabetes and hypertension. Asia Pac J Clin Nutr. 2006;15(1):107.

[108] Karthik D, Viswanathan P, Anuradha CV. Administration of rosmarinic acid reduces cardiopathology and blood pressure through inhibition of p22phox NADPH oxidase in fructose-fed hypertensive rats. J Cardiovasc Pharmacol. 2011;58(5):514-21.

[109] Posadas SJ, Caz V, Largo C, De la Gándara B, Matallanas B, Reglero G, et al. Protective effect of supercritical fluid rosemary extract, Rosmarinus officinalis, on antioxidants of major organs of aged rats. Exp Gerontol. 2009;44(6):383-9.

[110] Ullevig SL, Zhao Q, Zamora D, Asmis R. Ursolic acid protects diabetic mice against monocyte dysfunction and accelerated atherosclerosis. Atherosclerosis. 2011;219(2):409-16.

[111] Tsai C-W, Liu K-L, Lin Y-R, Kuo W-C. The mechanisms of carnosic acid attenuates tumor necrosis factor- $\alpha$-mediated inflammation and insulin resistance in 3T3-L1 adipocytes. Mol Nutr Food Res. 2014;58(4):654-64.

[112] Yam D, Bott-Kanner G, Friedman J, Genin I, Klainman E, Shinitzky M. Omega-3 fatty acids reduce hyperlipidaemia, hyperinsulinaemia and hypertension in cardiovascular patients. J Clin Basic Cardiol. 2002;5(3):229-31.

[113] Oxidative stress and left ventricular remodelling after myocardial infarction | Cardiovascular Research | Oxford Academic [Internet]. [cited 2020 Jun 19]. Available from: https://academic.oup.com/cardiovascres/article/81/3/457/1745887

[114] Genena AK, Hense H, Smânia Junior A, Souza SM de. Rosemary (Rosmarinus officinalis): a study of the composition, antioxidant and antimicrobial activities of extracts obtained with supercritical carbon dioxide. Food Sci Technol. 2008;28(2):463-9.

[115] de Oliveira JR, Camargo SEA, de Oliveira LD. Rosmarinus officinalis L. (rosemary) as therapeutic and prophylactic agent. J Biomed Sci. 2019;26(1):5.

[116] Wu Y, Xu X, Chen Z, Duan J, Hashimoto K, Yang L, et al. Nervous system involvement after infection with COVID-19 and other coronaviruses. Brain Behav Immun [Internet]. 2020 Mar 30 [cited 2020 Apr 12]; Available from: http://www.sciencedirect.com/science/article/pii/S0889159120303573

[117] Neurological Manifestations of Hospitalized Patients with COVID-19 in Wuhan, China: A Retrospective Case Series Study by Ling Mao, Mengdie Wang, Shengcai Chen, Quanwei He, Jiang Chang, Candong Hong, Yifan Zhou, David Wang, Xiaoping Miao, Yu Hu, Yanan Li, Huijuan Jin, Bo Hu: SSRN [Internet]. [cited 2020 Apr 13]. Available from: https://papers.ssrn.com/sol3/papers.cfm?abstract_id=3544840

[118] Giacomelli A, Pezzati L, Conti F, Bernacchia D, Siano M, Oreni L, et al. Self-reported olfactory and taste disorders in SARS-CoV-2 patients: a cross-sectional study. Clin Infect Dis. 2020; ciaa330.

[119] Gu J, Gong E, Zhang B, Zheng J, Gao Z, Zhong Y, et al. Multiple organ infection and the pathogenesis of SARS. J Exp Med. 2005;202(3):415-24.

[120] Xu J, Zhong S, Liu J, Li L, Li Y, Wu X, et al. Detection of Severe Acute Respiratory Syndrome Coronavirus in the Brain: Potential Role of the Chemokine Mig in Pathogenesis. Clin Infect Dis. 2005;41(8):1089-96. 
[121] Miller AJ, Arnold AC. The renin-angiotensin system in cardiovascular autonomic control: recent developments and clinical implications. Clin Auton Res. 2019;29(2):231-43.

[122] Harmer D, Gilbert M, Borman R, Clark KL. Quantitative mRNA expression profiling of ACE 2, a novel homologue of angiotensin converting enzyme. FEBS Lett. 2002;532(1-2):107-10.

[123] Imai Y, Kuba K, Rao S, Huan Y, Guo F, Guan B, et al. Angiotensin-converting enzyme 2 protects from severe acute lung failure. Nature. 2005;436(7047):112-6.

[124] Netland J, Meyerholz DK, Moore S, Cassell M, Perlman S. Severe Acute Respiratory Syndrome Coronavirus Infection Causes Neuronal Death in the Absence of Encephalitis in Mice Transgenic for Human ACE2. J Virol. 2008;82(15):7264-75.

[125] McCray PB, Pewe L, Wohlford-Lenane C, Hickey M, Manzel L, Shi L, et al. Lethal Infection of K18-hACE2 Mice Infected with Severe Acute Respiratory Syndrome Coronavirus. J Virol. 2007;81(2):813-21.

[126] Proinflammatory mediators released by activated microglia induces neuronal death in Japanese encephalitis - Ghoshal - 2007 - Glia - Wiley Online Library [Internet]. [cited 2020 Apr 15]. Available from: https://onlinelibrary.wiley.com/doi/epdf/10.1002/glia.20474

[127] Frontiers | Neurologic Alterations Due to Respiratory Virus Infections | Cellular Neuroscience [Internet]. [cited 2020 Apr 15]. Available from: https://www.frontiersin.org/articles/10.3389/fncel.2018.00386/full

[128] Yamada M, Ono K, Hamaguchi T, Noguchi-Shinohara M. Natural phenolic compounds as therapeutic and preventive agents for cerebral amyloidosis. In: Natural Compounds as Therapeutic Agents for Amyloidogenic Diseases. Springer; 2015. pp. 79-94.

[129] Hosseinzadeh H, Karimi GH, Noubakht M. Effects of Rosmarinus officinalis L. aerial parts essential oil on intact memory and scopolamine-induced learning deficits in rats performing the morris water maze task. 2004;

[130] Satoh T, Kosaka K, Itoh K, Kobayashi A, Yamamoto M, Shimojo Y, et al. Carnosic acid, a catechol-type electrophilic compound, protects neurons both in vitro and in vivo through activation of the Keap1/Nrf2 pathway via S-alkylation of targeted cysteines on Keap1. J Neurochem. 2008;104(4):1116-31.

[131] Kayashima T, Matsubara K. Antiangiogenic Effect of Carnosic Acid and Carnosol, Neuroprotective Compounds in Rosemary Leaves. Biosci Biotechnol Biochem. 2012;1111292741-1111292741.

[132] Seyedemadi P, Rahnema M, Bigdeli MR, Oryan S, Rafati H. The Neuroprotective Effect of Rosemary (Rosmarinus officinalis L.) Hydro-alcoholic Extract on Cerebral Ischemic Tolerance in Experimental Stroke. Iran J Pharm Res IJPR. 2016;15(4):875-83.

[133] Nolkemper S, Reichling J, Stintzing FC, Carle R, Schnitzler P. Antiviral effect of aqueous extracts from species of the Lamiaceae family against Herpes simplex virus type 1 and type 2 in vitro. Planta Med. 2006;72(15):1378-82.

[134] Mukhtar M, Arshad M, Ahmad M, Pomerantz RJ, Wigdahl B, Parveen Z. Antiviral potentials of medicinal plants. Virus Res. 2008;131(2):111-20.

[135] Bekut M, Brkić S, Kladar N, Dragović G, Gavarić N, Božin B. Potential of selected Lamiaceae plants in anti (retro) viral therapy. Pharmacol Res. 2018;133:301-14.

[136] Aruoma O, Spencer J, Rossi R, Aeschbach R, Khan A, Mahmood N, et al. An evaluation of the antioxidant and antiviral action of extracts of rosemary and Provencal herbs. Food Chem Toxicol. 1996;34(5):449-56.

[137] Shin H-B, Choi M-S, Ryu B, Lee N-R, Kim H-I, Choi H-E, et al. Antiviral activity of carnosic acid against respiratory syncytial virus. Virol J. 2013;10(1):1-11.

[138] Chung Y-C, Hsieh F-C, Lin Y-J, Wu T-Y, Lin C-W, Lin C-T, et al. Magnesium lithospermate B and rosmarinic acid, two compounds present in Salvia miltiorrhiza, have potent antiviral activity against enterovirus 71 infections. Eur J Pharmacol. 2015;755:127-33.

[139] Swarup V, Ghosh J, Ghosh S, Saxena A, Basu A. Antiviral and anti-inflammatory effects of rosmarinic acid in an experimental murine model of Japanese encephalitis. Antimicrob Agents Chemother. 2007;51(9):3367-70. 